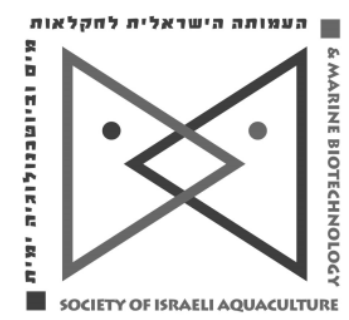

The IJA appears exclusively as a peer-reviewed on-line openaccess journal at http://www.siamb.org.il. To read papers free of charge, please register online at registration form.

Sale of IJA papers is strictly forbidden.

\title{
Effects of Air Exposure and Re-Submersion on Oxidative Stress of Marine Gastropod, Babylonia areolata
}

\author{
Hui-Ling Liu, Shi-Ping Yang *, Wen-Jun Guo, Zhen-Hua Tan, \\ Siuming Francis Chan
}

Fisheries College, Guangdong Ocean University, Zhanjiang, China

Keywords: air exposure; re-submersion; oxidative stress; Babylonia areolata

\begin{abstract}
The effects of air exposure on the antioxidant capacity of marine gastropod, Babylonia areolata, were evaluated. Superoxide dismutase (SOD) activity, malondialdehyde (MDA) content, and total antioxidant capacity (T-AOC) levels in the muscle and hepatopancreas in $B$. areolata were measured after air exposure and re-submersion. Results showed that SOD activity minimally increased in the hepatopancreas and muscle, after air exposure for 4 h. SOD activity in the hepatopancreas was lower than the normal level after $20 \mathrm{~h}$ of air exposure and air exposure followed by $4 \mathrm{~h}$ of re-submersion. T-AOC levels in the hepatopancreas and muscle of $B$. areolata decreased significantly $(P<0.05)$ following the period of air exposure. MDA content in the hepatopancreas of $B$. areolata subjected to air exposure for 24 and $28 \mathrm{~h}$ was significantly higher than the normal level. SOD activity in the hepatopancreas and T$A O C$ level in the hepatopancreas and muscle of $B$. areolata recovered to the normal level after $12 \mathrm{~h}$ of air exposure followed by $8 \mathrm{~h}$ of re-submersion. Air exposure can cause oxidative damage to $B$. areolata. The antioxidative system can be restored after air exposure for less than $12 \mathrm{~h}$ followed by re-submersion for $8 \mathrm{~h}$.
\end{abstract}

* Corresponding author. e-mail: Shi-Ping Yang, E-mail: ysp20010@sina.com 


\section{Introduction}

Normal oxygen consumption by aerobic organisms produces potentially reactive oxygen species (ROS), including superoxide $\left(\mathrm{O}_{2}^{-}\right)$and hydrogen peroxide $\left(\mathrm{H}_{2} \mathrm{O}_{2}\right)$ (Fridovich et al., 2004). ROS play a crucial role in various physiological processes. In the intertidal zone culture model, Babylonia areolata lives in the intertidal zone, which is a rigorous environment with extreme oxygen variations. To survive in this environment, $B$. areolata must endure periodic changes in oxygen, water availability, salinity, and temperature. The most serious situation is air exposure. Furthermore, juvenile $B$. areolata are often cultured in concrete ponds and transported to the intertidal zone. $B$. areolata suffer various forms of stress due to current handling practices, air exposure, re-immersion, and size selection. Air exposure is harmful to shellfish because it affects antioxidant defenses, immune responses, acid base status, respiration, energy-producing mechanisms, and survival (Chen et al., 2007; Dwyer and Burnett, 1996; Ellen et al., 2010). Excessive ROS production can increase oxidative stress (Kim et al., 2009). Environmental stresses, including air exposure, temperature, $\mathrm{pH}$, algal toxin, and metals, induce a generation of ROS in shellfish (Almeida et al., 2004; Almeida and Bainy 2006; Qiu et al., 2013; Hu et al., 2015). Marine coastal ecosystems contain varied oxygen concentrations. Intertidal organisms must cope daily with large oxygen variations. These organisms are exposed to air twice a day during low tide and thus experience periodic hypoxia or anoxia. With incoming tides, tissues undergo rapid re-oxygenation, which potentially leads to hyperoxia (Sussarellu et al., 2012). ROS production increased significantly in scallops (Chlamys farreri) exposed to air at $17^{\circ} \mathrm{C}$ and $25^{\circ} \mathrm{C}$ (Chen et al., 2007).

The spotted babylon $B$. areolata, is widely distributed from Sri Lanka and the Nicobar Islands through the Gulf of Siam, along the Vietnamese and Chinese coast to Taiwan (Regteren and Gittenberger, 1981). B. areolata has been a commercially important aquaculture species in China and Thailand but in nature, its numbers are decreasing (Guilan et al., 2013; Chaitanawisuti et al., 2002). The annual output of $B$. areolata is more than $1,000,000 \mathrm{~kg}$, which corresponds to more than $\$ 15$ million in China (Guilan et al., 2013). There are several models for culturing this species, including flow-through and static seawater systems in concrete/canvas ponds, earthen pond culture model, and the intertidal zone culture model (Kritsanapuntu al., 2009).

To the best of our knowledge, there are few papers on the effects of air exposure and re-submersion on oxidative stress of shellfish species namely on the bivalve Perna perna (Almeida et al., 2005), C. farreri (Chen et al., 2007), Crassostrea virginica (Willson and Burnett, 2000), and freshwater gastropods Nacella concinna (Ellen et al., 2010), and Cipangopaludina chinensis malleata (Havel, 2011).

$B$. areolata is a marine gastropod that lives in intertidal zones where there are extreme oxygen variations. Since we found no information on the response of antioxidant enzyme activities to air exposure followed by re-submersion, we studied the effects of air exposure and re-submersion on the behavior and oxidant levels of $B$. areolata. Superoxide dismutase (SOD) activity, total antioxidative capacity (T-AOC) level, and malondialdehyde (MDA) content in the 
muscle and hepatopancreas were determined after exposure to air and resubmersion. This study aims to provide a base for selecting marine zones for culture, and for designing a suitable strategy to decrease oxidative stress and mortality of $B$. areolata during transfer and other aquaculture activities.

\section{Materials and Methods}

Experiments were conducted in Zhanjiang Tengfei Industry Co., Ltd. (Zhanjiang, Guangdong, P. R. China). A batch of apparently healthy B. areolata (mean body weight $13.5 \pm 0.5 \mathrm{~g}$ ) was transferred to the laboratory from the culture pond. Only healthy and undamaged individuals were selected and maintained in an airconditioned room at $28^{\circ} \mathrm{C}$. They were fasted for at least $12 \mathrm{~h}$ prior to the experiment.

The air exposure experiment was performed by placing them in individual opaque foam tanks ( $120 \mathrm{~L}$ capacity) without water but covered with wet gauze to maintain air humidity. Individuals were subjected to air exposure stress for 0,4 , $8,12,16,20,24$, and $28 \mathrm{~h}$. After air exposure at $28^{\circ} \mathrm{C}$, individuals at different points in time were re-submersed in aerated seawater $\left(28^{\circ} \mathrm{C}\right)$ for $4 \mathrm{~h}$. In another experiment, individuals exposed to air for $12 \mathrm{~h}$ were re-submersed in aerated seawater $\left(28^{\circ} \mathrm{C}\right)$ for $4,8,12,16,20$, and $24 \mathrm{~h}$. Various forms of behavior were observed after air exposure and re-submersion.

Samples of hepatopancreas (digestive gland) and foot muscle were collected after air exposure and/or re-submersion for analysis of antioxidant parameters. For each condition and sampling time (air exposure and re-submersion), 3 individuals were sampled and analyzed respectively. All B. areolata individuals were placed on ice prior to anesthetization and dissection. The excised hepatopancreas and muscle tissues were homogenized in Tris- $\mathrm{HCl}$ buffer $(\mathrm{pH} 7.4)$ at $4{ }^{\circ} \mathrm{C}$. The homogenates were centrifuged at $4000 \mathrm{~g}$ for $10 \mathrm{~min}$ at $4^{\circ} \mathrm{C}$, and the clear supernatant was directly used for antioxidant parameter analysis (Liu et al., 2015). SOD activity, T-AOC, and MDA content were evaluated using the corresponding commercial kits (Nanjing Jiancheng Bioengineering Institute, China) according to manufacturers' instructions.

Results were analyzed with one-way analysis of variance and Duncan's multiple comparisons of the means were used to determine statistical differences. Statistical analyses were performed using SPSS 11.5 for Windows (SPSS Inc., Chicago, IL, USA).

\section{Results}

The state of each gastropod's foot was observed. After exposure to air, individuals opened their operculum and extended their feet. The foot was spread out in the air and retracted quickly at a slight touch. All re-submersed individuals were able to crawl. After $16 \mathrm{~h}$ of air exposure, some (40\%) did not retract their foot into the shell completely when touched slightly but re-submersed individuals were able to crawl after $4 \mathrm{~h}$ of re-submersion. After $24 \mathrm{~h}$ of air exposure, individuals retracted their foot slowly when touched but could not retract fully into 
their shell. $40 \%$ could crawl after $4 \mathrm{~h}$ of re-submersion. After $28 \mathrm{~h}$ of air exposure, $20 \%$ of the individuals died. Five individuals were re-submersed in the water for $4 \mathrm{~h}$ but only one could crawl a short distance. The remaining four individuals could not crawl.

SOD activity in the hepatopancreas decreased significantly after $8 \mathrm{~h}$ of air exposure $(P<0.05)$ and showed a fluctuating trend (Fig.1.A). MDA content in the hepatopancreas was affected significantly $(P<0.05)$ by air exposure. MDA content reached the maximum value after $24 \mathrm{~h}$ of air exposure (Fig.1.B). T-AOC level in the hepatopancreas was also affected significantly $(P<0.05)$ by air exposure. T-AOC level reached the maximum value after $16 \mathrm{~h}$ of air exposure, and then decreased gradually after 20-28 h of air exposure (Fig.1C).

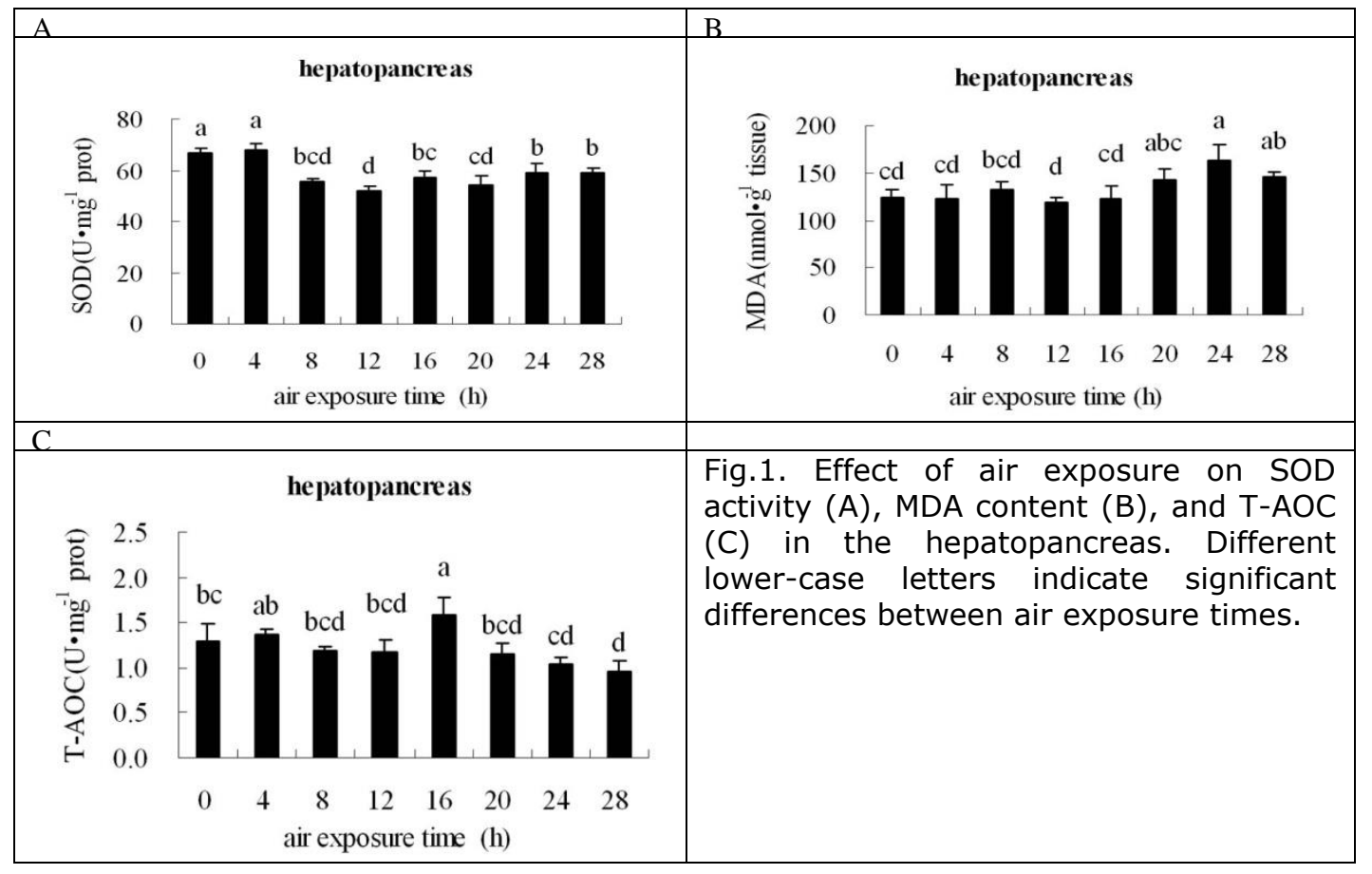

There was a significant difference $(P<0.05)$ in SOD activity in the muscle between groups. SOD activity reached a maximum value after 16 and $20 \mathrm{~h}$ of air exposure, and then decreased to a minimum value after $16 \mathrm{~h}$ of air exposure (Fig.2.A). Unexpectedly, MDA content in the muscle showed a decreasing trend, but $28 \mathrm{~h}$ was the only time point at which the MDA content was significantly lower $(P<0.05)$ than at other time points (Fig.2.B). T-AOC level in the muscle was affected significantly by air exposure $(P<0.05)$. T-AOC level decreased gradually with prolonged air exposure. 


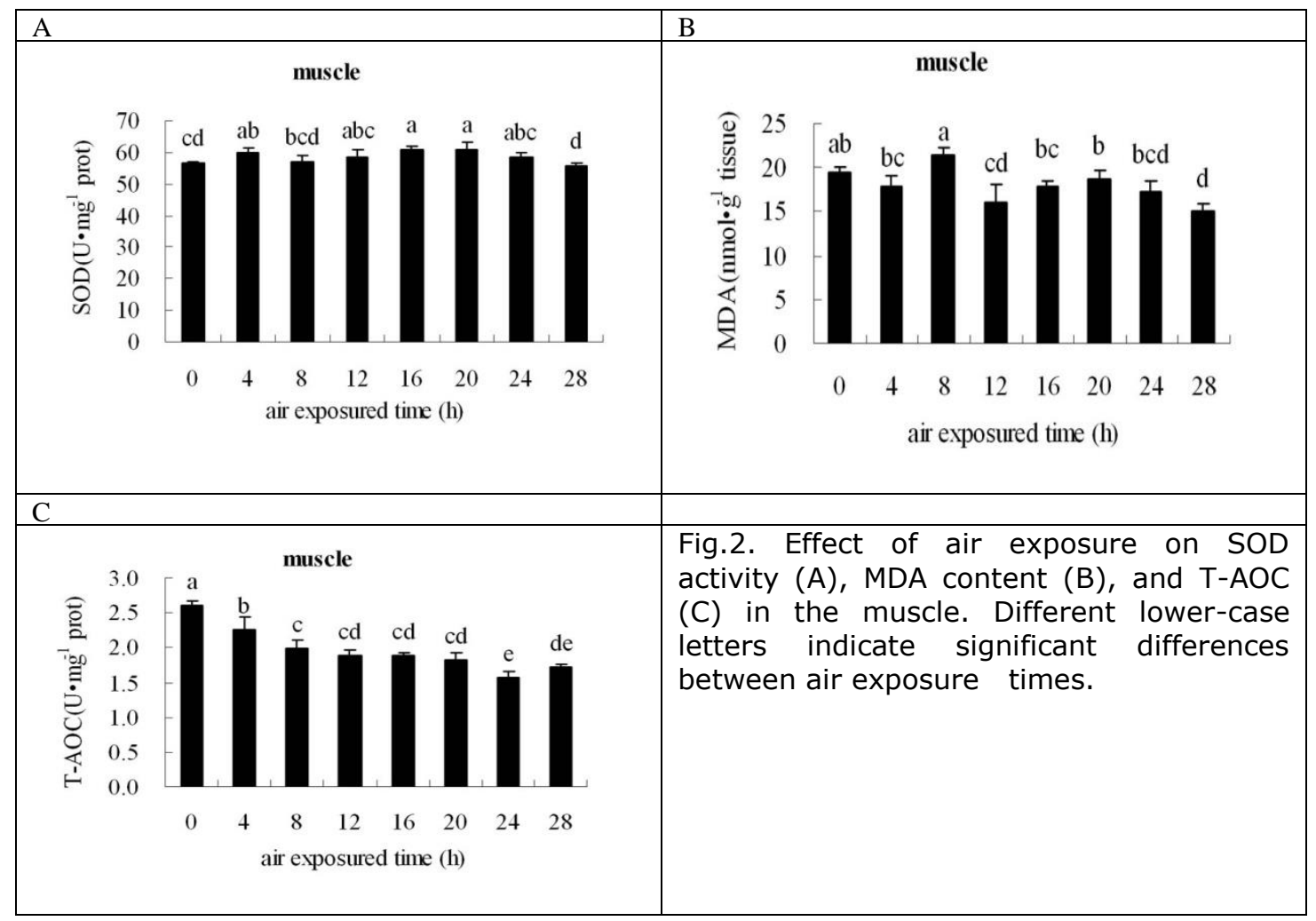

At different time points of air exposure at $28^{\circ} \mathrm{C}, \mathrm{B}$. areolata was re-submersed in aerated seawater for $4 \mathrm{~h}$. SOD activity in the hepatopancreas after 12 and $16 \mathrm{~h}$ of air exposure followed by $4 \mathrm{~h}$ of re-submersion was significantly higher $(P<$ 0.05 ) than at the other time points. SOD activity decreased after $16 \mathrm{~h}$ of air exposure followed by $4 \mathrm{~h}$ of re-submersion (Fig.3.A). MDA content in the hepatopancreas indicated a fluctuant change trend and reached a maximum value after $16 \mathrm{~h}$ of air exposure followed by $4 \mathrm{~h}$ of re-submersion. MDA content increased after 8,12 , and $16 \mathrm{~h}$ of air exposure followed by $4 \mathrm{~h}$ of re-submersion (Fig.3.B) compared with air exposure data (Fig.1.B). T-AOC levels increased significantly $(P<0.05)$ after $8 \mathrm{~h}$ of air exposure followed by $4 \mathrm{~h}$ of resubmersion, then decreased gradually (Fig.3.C). 


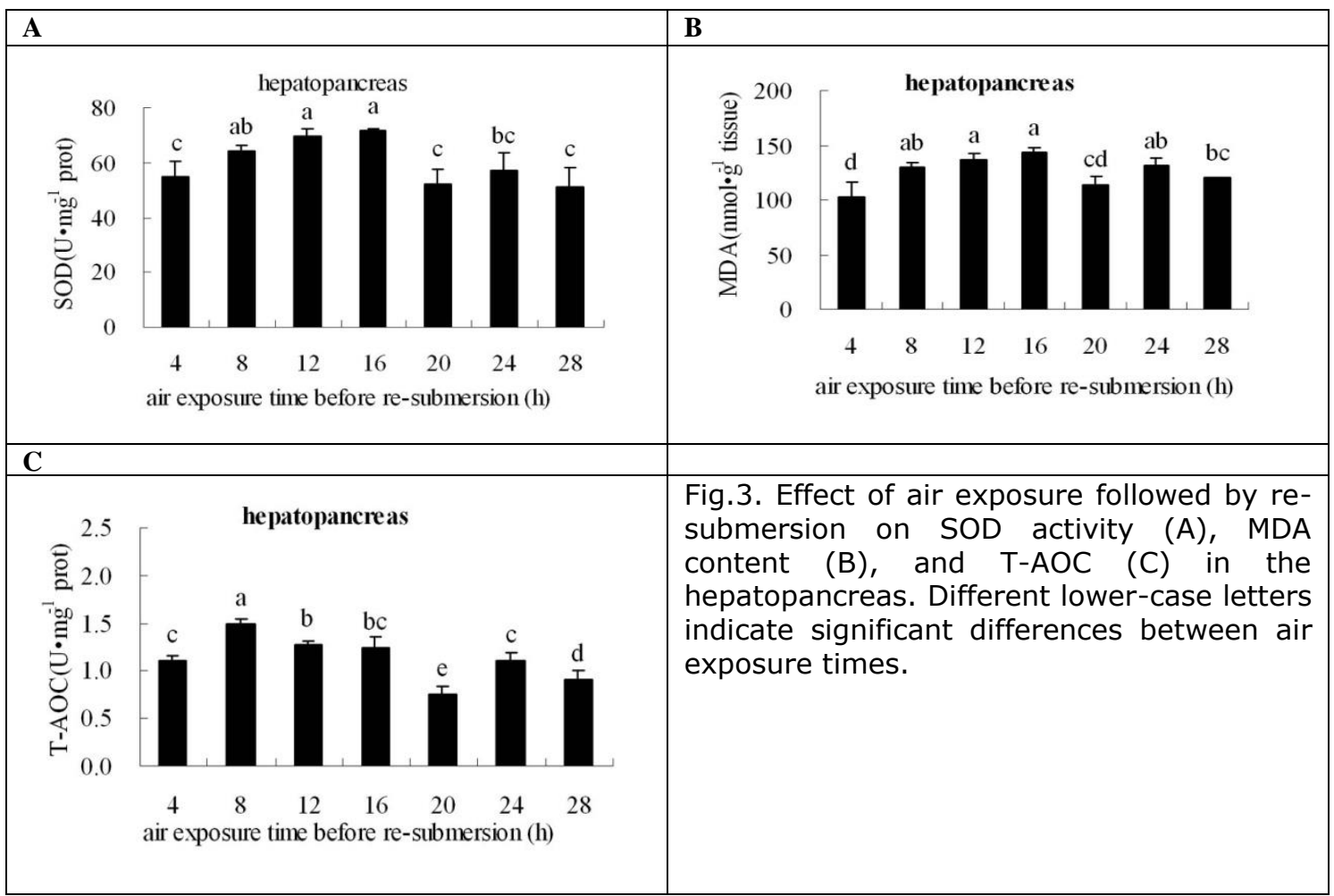

After air exposure which was followed by $4 \mathrm{~h}$ of re-submersion, the changing trend of SOD activity in the muscle was similar to that in the hepatopancreas. SOD activity increased significantly at several time points and then decreased (Fig.4.A). MDA content minimally changed and reached the maximum value after $12 \mathrm{~h}$ of air exposure followed by $4 \mathrm{~h}$ of re-submersion (Fig.4.B). The different changing trend of T-AOC levels was compared with air exposure data (Fig.2.C). TAOC levels increased significantly after 12 and $16 \mathrm{~h}$ of air exposure followed by 4 h of re-submersion $(P<0.05)$, then decreased. The lowest level of T-AOC was detected after $28 \mathrm{~h}$ of air exposure followed by $4 \mathrm{~h}$ of re-submersion (Fig.4.C).

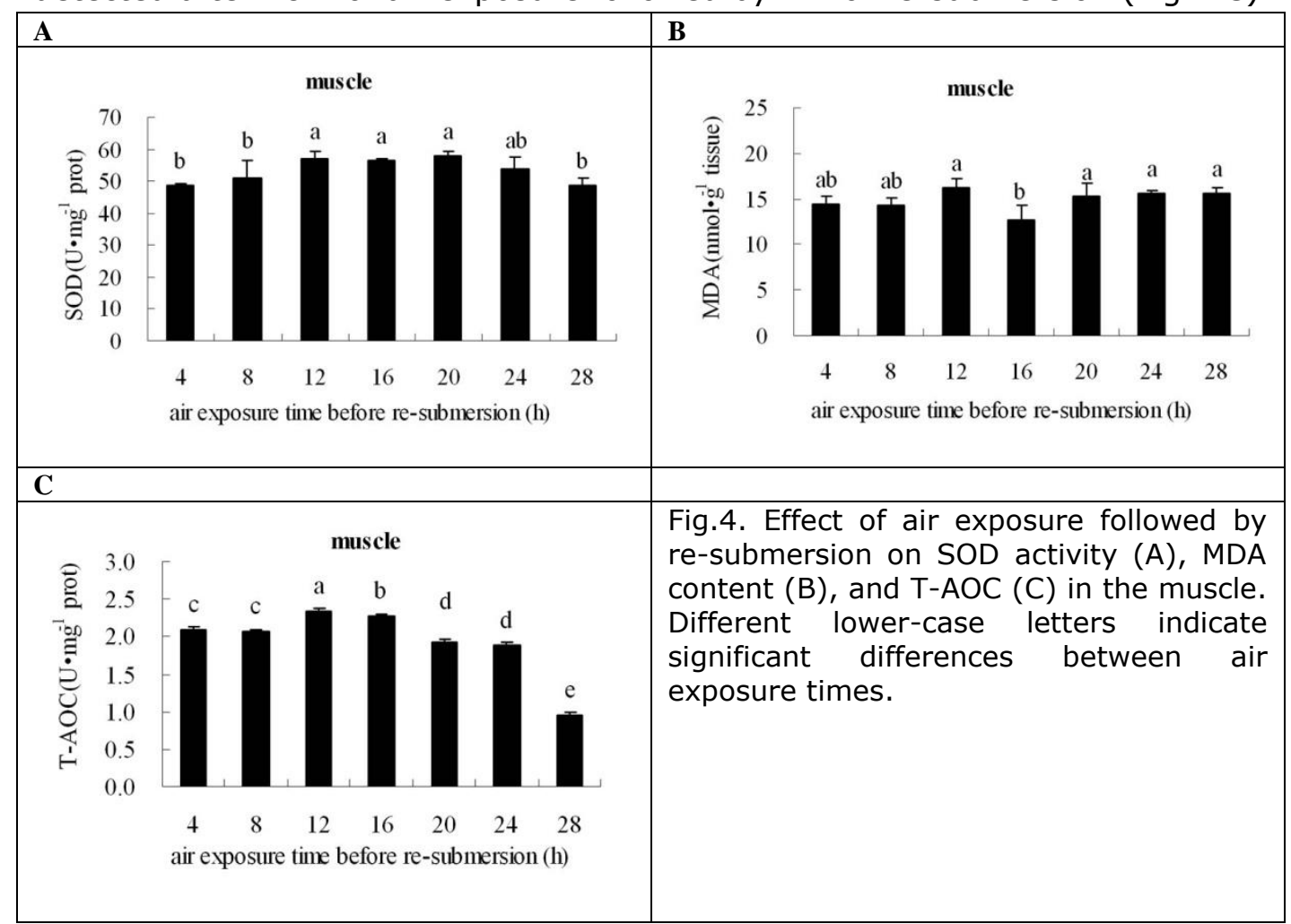


After $12 \mathrm{~h}$ of air exposure, B. areolata was re-submersed in aerated seawater $\left(28^{\circ} \mathrm{C}\right)$ for $4,8,12,16,20$, and $24 \mathrm{~h}$. Samples diagnosed showed that SOD activity in the hepatopancreas increased after $4 \mathrm{~h}$ of re-submersion, and reached normal levels after $20 \mathrm{~h}$ of re-submersion (Fig.5.A). No significant difference $(P>$ 0.05 ) was observed in MDA content at different times after re-submersion (Fig.5.B). During re-submersion, T-AOC levels did not change significantly in the hepatopancreas $(P>0.05)$. Standard deviations of T-AOC levels were high at each time point (Fig.5.C).

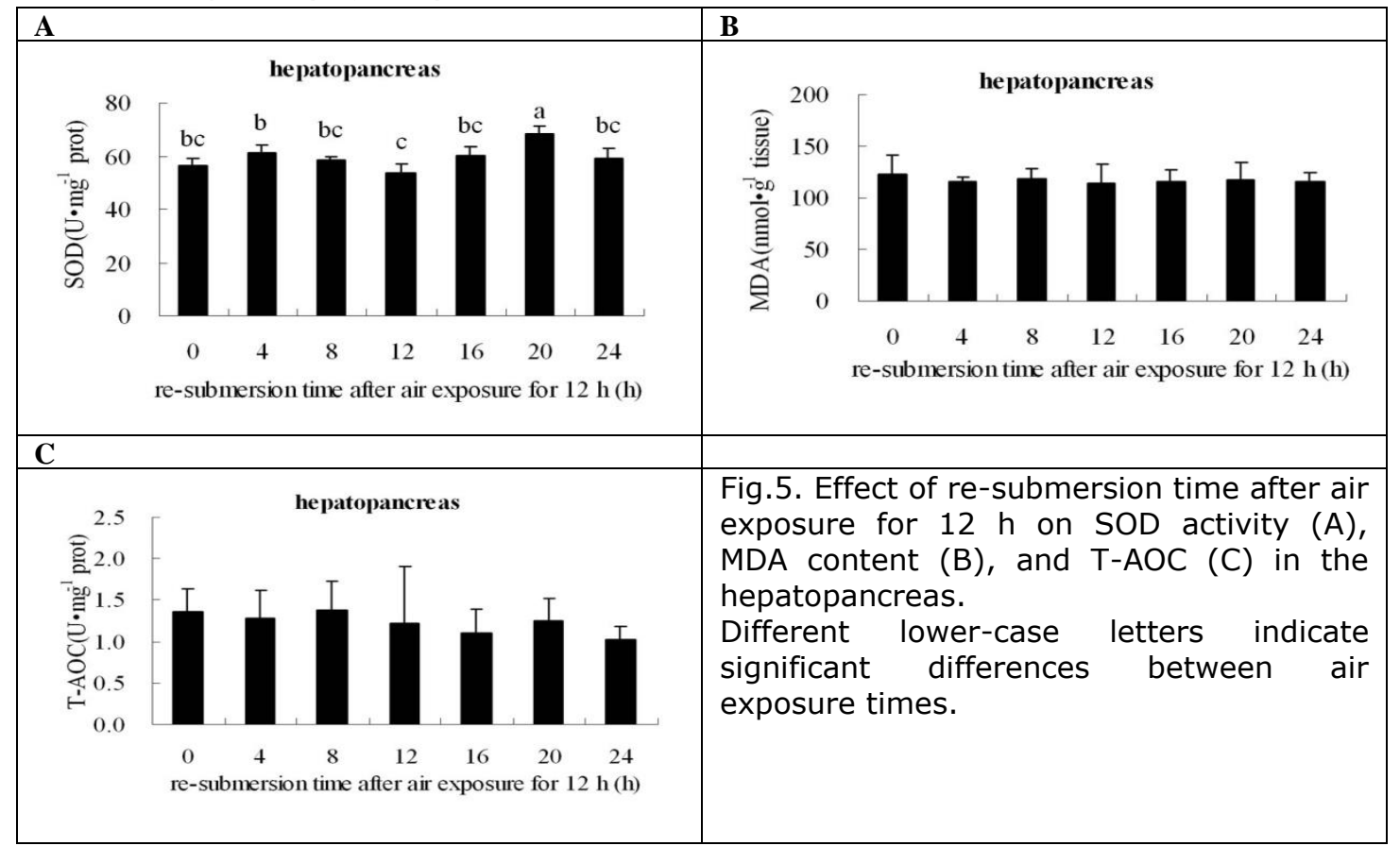

B. areolata was re-submersed in water after air exposure for $12 \mathrm{~h}$. SOD activity in the muscle decreased significantly after re-submersion with a minimum value after $12 \mathrm{~h}$ of re-submersion (Fig.6.A). MDA content reached the maximum value after $12 \mathrm{~h}$ of re-submersion (Fig.6.B). T-AOC levels increased after $8 \mathrm{~h}$ of re-submersion, which was approximately equal to the normal level (Fig.6.C). 


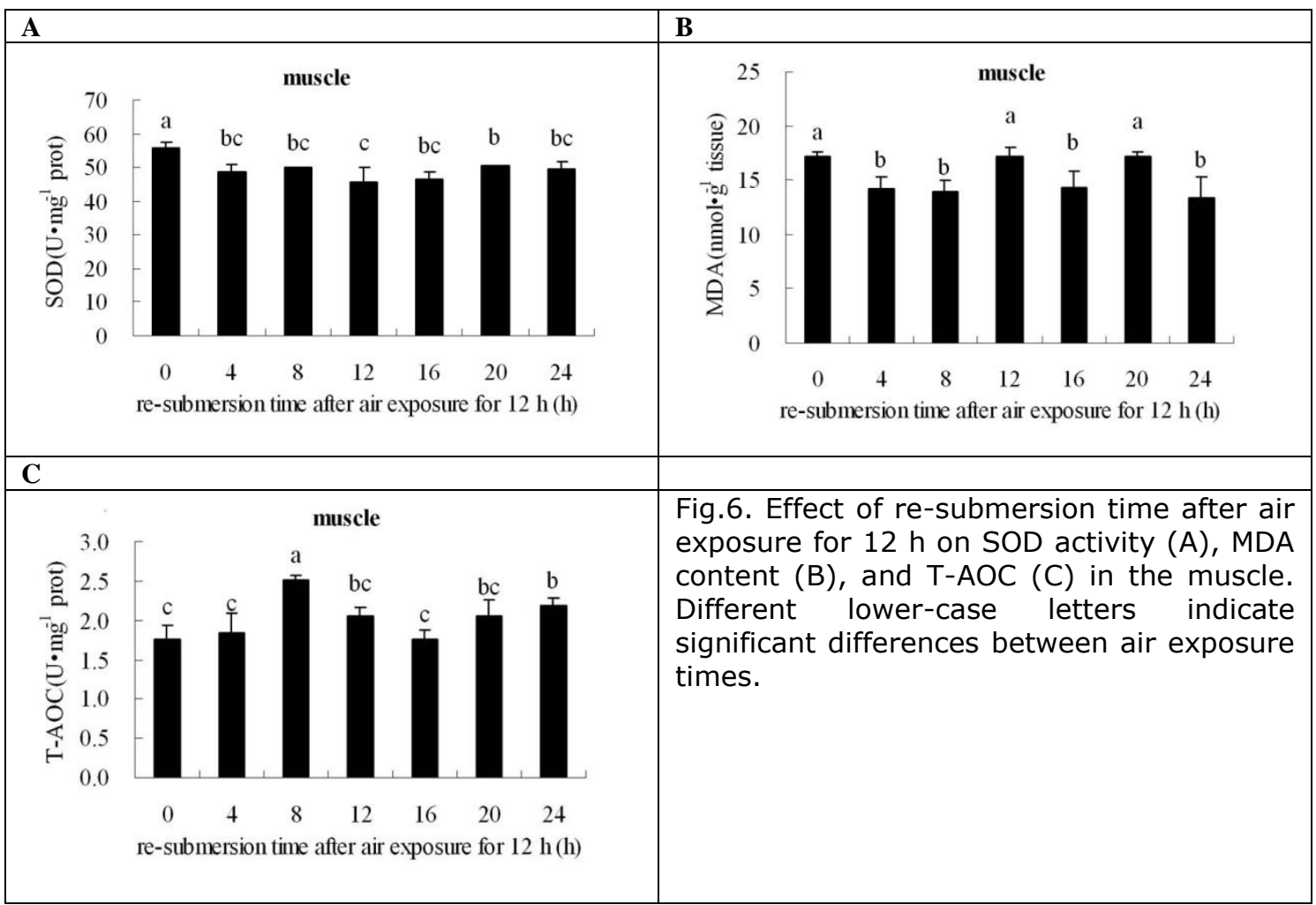

\section{Discussion}

Many mollusks exhibit high tolerance to air exposure. These organisms experience air exposure and variations in oxygen levels during the tidal cycle, and thus develop several mechanisms to survive and recover under air exposure at low tides. A strategy commonly used by intertidal animals during tidal exposure is reduction in oxygen consumption. $P$. canaliculus decreased their oxygen uptake by $87 \%$ under these conditions (Marsden and Weatherhead, 1998). Only $0.1 \%$ of normal oxygen uptake was retained by the oyster $C$. virginica exposed to air (Willson and Burnett, 2000). Shell gapping also enhances the survival of mollusks exposed to air. The gills may approach the aerial environment, and water around the gill surface contains high oxygen levels. Relative humidity also influenced the tolerance of Corbicula fluminea to air exposure at $15^{\circ} \mathrm{C}$ (Byrne and Dietz, 1988). The tolerance of $C$. chinensis juveniles to air exposure was also influenced by humidity (Havel, 2011). These findings indicate that high humidity can maintain the moisture of gills and increase oxygen. In the present study, the operculum of B. areolata opened during air exposure, and the feet were spread out in air to allow the gills to obtain oxygen. Under relatively high humidity conditions (mean $\mathrm{RH}$ of $69 \%$ ), mollusks showed high tolerance to air exposure (Byrne and Dietz, 1988). Strategies used by intertidal mollusks depend on their position in the intertidal zone. Low- and mid-littoral bivalve species generally close their valves and primarily rely on anaerobic pathways coupled with large reduction in metabolic rate (Mcmahon, 1988). Conversely, high littoral bivalves, such as Modiolus demissus, open their shells and obtain oxygen from the air (Lent, 1969).

In this study, SOD activity in the hepatopancreas of $B$. areolata exposed to air for $4 \mathrm{~h}$ was not significantly different $(P>0.05)$ from the normal level ( $0 \mathrm{~h}$ of air exposure) but SOD activity both in the hepatopancreas and in the muscle slightly increased after air exposure for $4 \mathrm{~h}$. $P$. perna exposed to the air for $4 \mathrm{~h}$ exhibited 
high SOD activity in the digestive gland (Almeida and Bainy, 2006). This pattern of increase of some antioxidant enzyme activities was also found in other animals, such as Paralomis granulosa (Romero et al., 2011), C. farreri (Chen et al., 2007), and Litopenaeus vannamei (Liu et al., 2015). This response could be a preparative mechanism against oxidative stress during re-submersion, which could explain the low SOD activity after 4 and $8 \mathrm{~h}$ of air exposure followed by $4 \mathrm{~h}$ of re-submersion. However, SOD activity in the hepatopancreas was low after 8 and $12 \mathrm{~h}$ of air exposure. This trend indicated that animals switch from normal metabolism to low-oxygen consumption metabolism. This time-course response of SOD activity was also observed in P. Perna (Almeida et al., 2005).

During re-submersion, SOD activity in $B$. areolata showed a time-course response, which was affected significantly by duration of air exposure. SOD activity in the hepatopancreas was significantly higher $(P<0.05)$ after 8,12 , and $16 \mathrm{~h}$ of air exposure followed by $4 \mathrm{~h}$ of re-submersion than at the other time points. SOD activity both after $20 \mathrm{~h}$ of air exposure and air exposure followed by $4 \mathrm{~h}$ of re-submersion was lower than the normal level. This finding indicated that $16 \mathrm{~h}$ was the maximum time required by $B$. areolata to sustain normal antioxidant function after air exposure followed by re-submersion.

T-AOC comprises enzymatic and non-enzymatic antioxidants, the nonenzymatic antioxidants include glutathione (GSH), ascorbic acid, carotenoids, and their derivatives, etc. (Mahfouz et al., 2009). T-AOC levels in the hepatopancreas and muscle of $B$. areolata decreased significantly $(P<0.05)$ after air exposure. During air exposure, non-enzymatic antioxidants were mainly absorbed in these tissues. These results suggested that non-enzymatic antioxidants fulfill an important role against ROS or oxidative damage during air exposure. The importance of non-enzymatic antioxidants in protecting Scrobicularia plana from mercury pro-oxidant action was highlighted by investigating changes in ascorbic acid and GSH (Ahmad et al., 2012). During air exposure and re-submersion, the changing pattern of T-AOC levels in the hepatopancreas and muscle of $B$. areolata is similar to that of L. vannamei (Liu et al., 2015).

Lipid peroxidation leads to the formation of secondary products, such as MDA. This process has been evaluated as an indicator of environmental stresses in different tissues of the mussel P. Perna (Almeida et al., 2003; Almeida et al., 2004; Filho et al., 2001). When exposed to air for $24 \mathrm{~h}$, the levels of lipid peroxidation in gills and digestive glands of $P$. perna increased significantly (Almeida et al., 2005). After air exposure, lipid oxidation increased in the tissues of Antarctic limpet $N$. cocinna and P. granulose (Ellen et al., 2010; Romero et al., 2007). In the present study, B. areolata exposed to air for 24 and $28 \mathrm{~h}$ showed significantly higher MDA content in the hepatopancreas compared with the normal level, however, MDA content in the muscle, did not increase significantly after air exposure. The results appear to be associated with the different tissues; hepatopancreas was more prone to oxidative damage than muscle. The underlying reason remains unclear but maybe be due to structural and functional 
differences between the two tissue types. After $12 \mathrm{~h}$ of air exposure followed by re-submersion for $8 \mathrm{~h}$, SOD activity in the hepatopancreas and T-AOC levels in the hepatopancreas and muscle of $B$. areolata recovered to normal levels. MDA content in the hepatopancreas and muscle of $B$. areolata after air exposure for 12 $\mathrm{h}$ and re-submission for $12 \mathrm{~h}$ approached normal levels.

In summary, air exposure can cause oxidative damage to $B$. areolata. Oxidative damage can be restored when individuals are returned to their normal habitat, but the oxidative damage is irreversible and eventually causes death in animals after long periods of air exposure. The results of this study indicated that the critical time-period of air exposure is probably at $12 \mathrm{~h}$ for $B$. areolata. This information is useful to minimize oxidative stress in commercial aquaculture, and the capture process.

\section{Acknowledgements}

This work was supported by Science and Technology Plan Projects of Guangdong province (NO.2012B020415006) and Ocean and Fishery Bureau of Guangdong Project (NO.201508A05). We would also like to thank all the people who have dedicated their time to the experiments.

\section{References}

Ahmad I., Mohmood I., Coelho J.P., Pacheco M., Santos M.A., Duarte A.C. and E. Pereira, 2012. Role of non-enzymatic antioxidants on the bivalves' adaptation to environmental mercury: Organ-specificities and age effect in Scrobicularia plana inhabiting a contaminated lagoon. Environ. Pollu., 163: 218225.

Almeida E.A., and A.C.D. Bainy, 2006. Effects of aerial exposure on antioxidant defenses in the brown mussel Perna perna. Braz. J. Biol. Techno., 49(2): 225229.

Almeida E.A., Bainy A.C.D., Dafre A.L., Gomes, O.F., Medeiros M.H.G, and P. Di Mascio, 2005. Oxidative stress in digestive gland and gill of the brown mussel (Perna perna) exposed to air and re-submersed. J. Experim. Mar. Biol., 318(1): 21-30.

Almeida E.A., Bainy A.C.D, Loureiro A.P.M., Medeiros M.H.G., and P. Di Mascio, 2003. DNA and lipid damage in the brown mussel Perna perna from a contaminated site. Bull Environ. Contam. Toxicol., 71: 270-275.

Almeida E.A., Miyamoto S., Bainy A.C.D., Medeiros M.H.G., and P. Di Mascio, 2004. Protective effect of phospholipid hydro-peroxide glutathione peroxidase (PHGPX) against lipid perox-idation in mussels Perna perna exposed to different metals. Mar. Pollut. Bull 49: 386-392.

Byrne R.A., and T.H. Dietz, 1988. Temperature and relative humidity effects on aerial exposure tolerance in the freshwater bivalve Corbicula fluminea. Biol. Bull, 175(2): 253-260.

Chaitanawisuti N., Kritsanapuntu A., and Y. Natsukari, 2002. Economic analysis of a pilot commercial production for spotted babylon, Babylonia areolata Link 1807, marketable sizes using a flow-through culture system in Thailand. Aquac. Res. 33: 1-8. 
Chen M.Y., Yang H.S., Delaporte M., Zhao S.J., and K. Xing, 2007. Immune responses of the scallop Chlamys farreri after air exposure to different temperatures. J. Experim. Mar. Biol., 345(1): 52-60.

Dwyer J.J., and L.E. Burnett, 1996. Acid base status of the oyster Crassostrea virginica in response to air exposure and to infections by Perkinsus marinus. Biol. Bull, 190(1): 139-147.

Ellen W., Michael K., and A. Doris, 2010. Differences in heavy metal concentrations and in the response of the antioxidant system to hypoxia and air exposure in the Antarctic limpet Nacella concinna. Mar. Environ. Res., 69(3): 127135.

Filho D.W., Tribess T., Gáspari C., Claudio F.D., Torres M.A, and A.R.M. Magalhães, 2001. Seasonal changes in antioxidant defenses of the digestive gland of the brown mussel (Perna perna). Aquaculture, 203(1-2): 149-158.

Fridovich I., 2004. Mitochondria: are they the seat of senescence? Aging Cell, 3, 13-16.

Guilan D., Zhaoxia Z., and K. Caihuan, 2013. Phagocytosis and respiratory burst activity of haemocytes from the ivory snail, Babylonia areolata. Fish Shellfish Immunol., 35(2): 366-374.

Havel J. E., 2011 Survival of the exotic Chinese mystery snail (Cipangopaludina chinensis malleata) during air exposure and implications for overland dispersal by boats. Hydrobiologia, 668(1): 195-202.

Hu M., Li L., Sui Y., Li J., Wang Y., Lu W., and S. Dupont, 2015. Effect of pH and temperature on antioxidant responses of the thick shell mussel Mytilus coruscus. Fish Shellfish Immunol., 46(2): 573-583.

Kim Y.S., Ke F., and Q.Y. Zhang, 2009. Effect of $\beta$-glucan on activity of antioxidant enzymes and $\mathrm{Mx}$ gene expression in virus infected grass carp. Fish Shellfish Immunol., 27(2): 336-340.

Kritsanapuntu S., Chaitanawisuti N., and Y. Natsukari, 2009. Growth and water quality for growing-out of juvenile spotted Babylon, Babylonia areolata, at different water-exchange regimes in a large-scale operation of earthen ponds. Aquac. Int. 17(1): 77-84.

Lent C.M., 1969. Adaptations of the ribbed mussel, Modiolus demissus (Dillwyn), to the intertidal habitat. Amer. Zool., 9(2): 283-292.

Liu H.L., Yang S.P., Wang C.G., Chan S.M., Wang W.X., Feng Z.H., and C.B. Sun, 2015. Effect of air exposure and resubmersion on the behavior and oxidative stress of Pacific white shrimp Litopenaeus vannamei. N. Amer. J. Aquacult., 77(1): 43-49.

Mahfouz R., Sharma R., Sharma D., Sabanegh E., and A. Agarwal, 2009. Diagnostic value of the total antioxidant capacity (TAC) in human seminal plasma. Fertil. Steril., 91: 805-811.

Marsden I.D., and M.A. Weatherhead, 1998. Effects of aerial exposure on oxygen consumption by the New Zealand mussel Perna canaliculus (Gmelin, 1791) from an intertidal habitat. J. Exp. Mar. Biol. Ecol., 230(1): 15-29. 
Mcmahon R.F., 1988. Respiratory response to periodic emergence in intertidal molluscs. Amer. Zool., 1988, 28(1): 97-114.

Qiu J., Fan H., Li A., and F. Ma F, 2013. Effects of feeding alexandrium tamarense a paralytic shellfish toxin producer, on antioxidant enzymes in scallops (Patinopecten yessoensis) and mussels (Mytilus galloprovincialis). Aquaculture, 396(3): 76-81.

Regteren Av C.O., and E. Gittenberger, 1981. The genus Babylonia (Prosobranchia, Buccinidae). Zool. Verh., 188: 3-57.

Romero M., Ansaldo M., and G.A. Lovrich, 2007. Effect of aerial exposure on the antioxidant status in the subantarctic stone crab Paralomis granulose (Decapoda: Anomura). Comp. Biochem. Physiol. C, 146(1): 54-59.

Romero M., Tapella F., Sotelano M.P., Ansaldo M., and G.A. Lovrich, 2011. Oxidative stress in the subantarctic false king crab Paralomis granulosa during air exposure and subsequent re-submersion. Aquaculture, 319(1): 205-210.

Sussarellu R., Fabioux C., Sanchez M.C., Goïc N.L., Lambert C., Soudant P., and D.Moraga, 2012. Molecular and cellular response to short-term oxygen variations in the pacific oyster Crassostrea gigas. J. Exp. Mar. Biol. Ecol., 412(1): 87-95.

Willson L.L., and L.E. Burnett, 2000. Whole animal and gill tissue oxygen uptake in the eastern oyster, Crassostrea virginica: effects of hypoxia, hypercapnia, air exposure, and infection with the protozoan parasite Perkinsus marinus. J. Exp. Mar. Biol. Ecol., 246(2): 223-240. 